\title{
Mechanism of Suppression of Blood Glucose Level by Calcium Alginate in Rats
}

\author{
Yoko Idota, ${ }^{a, b}$ Takako Kato, ${ }^{a, b}$ Kazuyo Shiragami, ${ }^{c}$ Mariko Koike, ${ }^{c}$ Akari Yokoyama,,${ }^{a, b}$ \\ Hitoe Takahashi, ${ }^{a, b}$ Kentaro Yano, ${ }^{a}$ and Takuo Ogihara*,a,d \\ ${ }^{a}$ Laboratory of Biopharmaceutics, Faculty of Pharmacy, Takasaki University of Health and Welfare; 60 Nakaorui- \\ machi, Takasaki, Gunma 370-0033, Japan: ${ }^{b}$ Kendai Translational Research Center; 60 Nakaorui-machi, \\ Takasaki, Gunma 370-0033, Japan: ' Research and Development Department, Shimadaya Corporation; 2-1-30 \\ Musashino, Akishima, Tokyo 196-0021, Japan: and ${ }^{d}$ Laboratory of Clinical Pharmacokinetics, Graduate School of \\ Pharmaceutical Sciences, Takasaki University of Health and Welfare; 60 Nakaorui-machi, Takasaki, Gunma 370- \\ 0033, Japan. \\ Received February 25, 2018; accepted June 22, 2018; advance publication released online July 4, 2018
}

\begin{abstract}
Calcium alginate (Ca-Alg) is known to suppress the postprandial increase of blood glucose, and therefore may be helpful for preventing lifestyle-related diseases such as diabetes. In this work, we examined the mechanism of this effect. As $\alpha$-amylase activity and $\alpha$-glucosidase activity are involved in the digestion of starch, we examined the in vitro inhibitory effect of Ca-Alg on these enzymes. Ca-Alg showed little inhibition of $\alpha$-amylase, but markedly inhibited $\alpha$-glucosidase activity. The direct binding affinity of glucose for Ca-Alg was low. Also, Ca-Alg had essentially no effect on the membrane permeability of glucose. Therefore, we considered that the suppression of blood glucose by Ca-Alg is predominantly due to a decrease in the efficiency of starch digestion as a result of inhibition of $\alpha$-glucosidase, possibly due to increased viscosity of the gastrointestinal contents. Next, we investigated the optimum amount in the diet and the optimum particle size of Ca-Alg for suppressing postprandial blood glucose level in rats orally administered a diet containing starch with various amounts and particle sizes of Ca-Alg. We found that 5\% by weight of 270-mesh-pass Ca-Alg was most effective.
\end{abstract}

Key words calcium alginate; alginic acid; blood glucose level; $\alpha$-glucosidase (maltase); starch; particle size

Lifestyle-related diseases associated with high calorie intake and insufficient exercise, such as diabetes, hypertension and dyslipidemia, have become a significant social problem, ${ }^{1,2}$ and may lead to the development of cancer, heart disease and cerebrovascular disease, which are major causes of death in Japan. $^{3-10)}$ For example, diabetic patients may develop complications such as retinopathy, nephropathy and neuropathy, in addition to myocardial infarction, cerebral infarction and so on. ${ }^{11,12)}$ As many as 10 million people were suspected of having diabetes in Japan in 2016, and a similar number were at risk of developing diabetes. ${ }^{13)}$ Moreover, because the subjective symptoms are initially minor, many patients only become aware of the disease after it worsens, when complete recovery is difficult. Therefore, prevention is very important.

Glucose absorbed from the gastrointestinal tract is distributed to tissues via the systemic circulation under the control of insulin, and is stored and utilized as an energy source. Diabetes (particularly type 2) is caused by decreased production of insulin, leading to increased glucose levels in the blood. ${ }^{14,15)}$ Improvements in eating and exercise habits are recommended for the prevention of diabetes. Among eating habits, not overeating, ingestion of more vegetables, and eating slowly are recommended, because they help to prevent a sharp rise in blood glucose level after meals. ${ }^{16)}$

Alginate is a polysaccharide derived from brown algae. Sodium alginate (Na-Alg) is used as a health food or medicine because it has cholesterol-lowering and gastric mucosa-protective actions. In addition, it is used as a food additive (thickening stabilizer) and medicinal additive. ${ }^{17-20)}$ However, excessive intake of sodium is one of the risk factors for hypertension. ${ }^{21)}$
Therefore, if the calcium salt of alginic acid (Ca-Alg) has a similar effect of Na-Alg, it might be more beneficial than NaAlg.

We previously reported that $\mathrm{Ca}-\mathrm{Alg}$ promoted excretion of strontium and cesium in rats. ${ }^{22)}$ Moreover, we found that Ca-Alg inhibited the reabsorption of bile acids in the gastrointestinal tract and promoted the excretion of bile acids into feces, thereby enhancing the metabolism of cholesterol to bile acid in the liver and reducing the cholesterol level in blood. ${ }^{23)}$ In addition, it was reported that a rise in blood glucose level after eating a single portion of curry rice tended to be suppressed in adult male subjects when the rice was supplemented with Ca-Alg. ${ }^{24)}$ In the gastrointestinal tract, starch is firstly decomposed into maltose mainly by $\alpha$-amylase, and then further decomposed to glucose by $\alpha$-glucosidase (maltase). Glucose is absorbed via glucose transporters located on the cell membrane surface. Since Ca-Alg is not absorbed from the gastrointestinal tract, it should inhibit at least one of these processes to suppress the blood glucose level. Therefore, we examined which process is inhibited by $\mathrm{Ca}-\mathrm{Alg}$ in this study. We also investigated the optimal amount and particle size of $\mathrm{Ca}-\mathrm{Alg}$ in the diet to suppress the postprandial increase of blood glucose in rats.

\section{MATERIALS AND METHODS}

Chemicals Na-Alg and Ca-Alg (80, 150, and 270 mesh pass, average particle diameter $118.0,42.1$, and $12.3 \mu \mathrm{m}$, respectively; average molecular weight of both $\mathrm{Na}-\mathrm{Alg}$ and $\mathrm{Ca}-\mathrm{Alg}$ is $700 \mathrm{kDa}$ regardless of particle size) were supplied 
by Kimica Corporation (Tokyo, Japan). Soluble starch for biochemistry, $\alpha$-glucosidase activity assay kit, glucose, glucose measurement kit (Labo Assay ${ }^{\mathrm{TM}}$ Glucose), phloretin, and acarbose were purchased from Wako Pure Chemical Industries, Ltd. (Osaka, Japan). $\alpha$-Amylase from porcine pancreas (Type VI-B) was purchased from Sigma-Aldrich Co. LLC. (Tokyo, Japan). Maltose Assay Kit and Glucose Colorimetric/ Fluorometric Assay Kit were purchased from Bio Vision Inc. (California, U.S.A.). All other chemicals and solvents were analytical-grade or food-grade commercial products.

\section{In Vitro Experiments}

\section{Effect on $\alpha$-Amylase Activity}

Na-Alg aqueous solution $(50 \mu \mathrm{L} ; 3,6$, and $12 \mathrm{mg} / \mathrm{mL})$ was added to $100 \mu \mathrm{L}$ of a $4 \%$ starch solution $(0.1 \mathrm{M}$ phosphate buffer solution, $\mathrm{pH}$ 7.0). Calcium chloride aqueous solution $(20 \mu \mathrm{L}, 40 \mathrm{mg} / \mathrm{mL})$ was added to generate Ca-Alg in the solution. Although Na-Alg was used in place of water-insoluble $\mathrm{Ca}-\mathrm{Alg}$ for the in vitro experiments, the test solution contained $1.67 \mathrm{mM} \mathrm{Ca}^{2+}$, and it is considered that almost all $\mathrm{Alg}$ would have swiftly formed the $\mathrm{Ca}^{2+}$ salt. This mixture was incubated at $37^{\circ} \mathrm{C}$ for $5 \mathrm{~min}$, then $50 \mu \mathrm{L}$ (1 Unit) of $\alpha$-amylase solution $(0.1 \mathrm{M}$ phosphate buffer solution, $\mathrm{pH} 7.0)$ was added and incubation was continued at $37^{\circ} \mathrm{C}$ for $10 \mathrm{~min}$ (concentration in terms of Na-Alg: $0.68,1.36,2.73 \mathrm{mg} / \mathrm{mL}$ ). The reaction was terminated by heating at $100^{\circ} \mathrm{C}$ for $3 \mathrm{~min}$ with a Dry Thermo Unit (TAITEC). As a control, water was added instead of the Na-Alg aqueous solution, and inactivated enzyme solution was added for the blank. The solution after termination of the reaction was centrifuged $\left(15000 \times \mathbf{g}, 20 \mathrm{~min}, 4^{\circ} \mathrm{C}\right)$, and the amount of maltose in the supernatant was measured using a maltose assay kit. The production rate was calculated according to the following formula:

\section{Production rate $(\%)$ \\ $=$ (amount of maltose produced upon formation of Ca-Alg $/$ amount of maltose produced in control) $\times 100$}

\section{Effect on $\alpha$-Glucosidase Activity}

Na-Alg $(50 \mu \mathrm{L} ; 6,12 \mathrm{mg} / \mathrm{mL})$ was added to $100 \mu \mathrm{L}$ of $18.5 \mathrm{~mm}$ maltose solution $(100 \mathrm{~mm}$ maleic acid buffer solution, $\mathrm{pH}$ 6.0). Calcium chloride aqueous solution $(20 \mu \mathrm{L}, 40 \mathrm{mg} / \mathrm{mL})$ was added to generate $\mathrm{Ca}-\mathrm{Alg}$ in the solution. The solution was incubated at $37^{\circ} \mathrm{C}$ for $3 \mathrm{~min}$, then $50 \mu \mathrm{L}$ of $\alpha$-glucosidase solution (100 mm maleic acid buffer solution, $\mathrm{pH} 6.0$ ) was added, and the mixture was incubated at $37^{\circ} \mathrm{C}$ for $30 \mathrm{~min}$. After the reaction, $800 \mu \mathrm{L}$ of water was added. The reaction was terminated by heating at $100^{\circ} \mathrm{C}$ for $3 \mathrm{~min}$ with a Dry Thermo Unit. As a control, water was added instead of the Na-Alg aqueous solution. For the blank solution, the reaction was stopped immediately after adding the enzyme solution. The amount of glucose was measured using a glucose measurement kit. For the positive control, $1 \mu \mathrm{g} / \mathrm{mL}$ of acarbose was used instead of Na-Alg. The production rate was calculated in the same manner as the maltose production rate.

Affinity of Alg and Glucose To $3 \mathrm{~mL}$ of $9 \mathrm{~mm}$ calcium chloride aqueous solution, $3 \mathrm{~mL}$ of glucose solution $(0,30$, $90,300,900 \mathrm{~mm})$ was added. Next, $3 \mathrm{~mL}$ of a $9 \mathrm{mg} / \mathrm{mL} \mathrm{Na}$ Alg solution was added, and the mixture was stirred and left to stand. After $20 \mathrm{~min}, 0.5 \mathrm{~mL}$ of the solution was placed in a centrifugal filter unit (Amicon Ultra- $0.5 \mathrm{~mL} 3 \mathrm{~K}$, molecular fractionation amount of 3000 (Millipore)) and centrifuged $\left(15000 \times \mathbf{g}, 20 \mathrm{~min}, 4^{\circ} \mathrm{C}\right)$. The amount of glucose in the filtrate was measured using a glucose measurement kit. As a control, $3 \mathrm{~mL}$ of water was added instead of Na-Alg.

Effect of Na-Alg on Membrane Permeability of Glucose Caco-2 cells were obtained from American Type Culture Collection (Rockville, MD, U.S.A.) and cultivated as described previously. ${ }^{25)}$ All cells used in this study were at passage 54. The cells were grown for $21 \mathrm{~d}$ on a polycarbonate membrane (Transwell: $11.2 \mathrm{~mm}$ in diameter and $3.0 \mu \mathrm{m}$ pore size, effective area of $1 \mathrm{~cm}^{2}$, Costar, Bedford, MA, U.S.A.). Glucose-free Hank's Balanced Salt (HBS) was prepared and 2-morpholinoethanesulfonic acid (MES, for $\mathrm{pH}$ 6.5) or 2-[4-(2-hydroxyethyl)-1-piperazinyl]ethanesulfonic acid (HEPES, for $\mathrm{pH}$ 7.4) was added to form the buffer solution on the apical side $(\mathrm{pH} 6.5)$ or basal side $(\mathrm{pH} 7.4)$, respectively. Glucose (75 mm)/HBS-MES ( $\mathrm{pH} 6.5$ ) solution containing NaAlg $0,0.1$, and $0.5 \%$ was added to the apical side. Phloretin $(500 \mu \mathrm{M})$, a glucose transporter 2 (GLUT 2) inhibitor, was used as a positive control instead of Na-Alg. Samples were taken from the basal side at the designated times, and glucose was measured by colorimetric analysis using the Glucose Colorimetric/Fluorometric Assay Kit. The permeability coefficient was calculated.

In Vivo Experiments The animal study was performed according to the Guidelines for the Care and Use of Laboratory Animals at Takasaki University of Health and Welfare and approved by the Committee of Ethics of Animal Experimentation of the University. Specific-pathogen-free male Wistar rats at seven weeks of age were purchased from SLC Japan (Hamamatsu, Japan), and housed 1-3 animals per cage in a room kept under controlled conditions (temperature of $23 \pm 3^{\circ} \mathrm{C}$, humidity of $50 \pm 20 \%$ ) with a 12 -h light/dark cycle, and given free access to food and water.

After acclimation for one week, rats were randomized based on weight (177-207g) into 5 groups: starch with no CaAlg (control), or with Ca-Alg (3\%; 270 mesh pass, 5\%; 270 mesh pass, $5 \% ; 150$ mesh pass, or $5 \% ; 80$ mesh pass) $(n=3-4$ each). Rats were fasted for $1 \mathrm{~d}$ and then weighed. Blood was sampled from the tail vein, and the glucose level before administration $\left(C_{0}\right)$ was measured using a blood glucose level measuring device (Freestyle Libre Leader, Abbott). Water was added to the five types of starches with or without $\mathrm{Ca}-\mathrm{Alg}$ and the mixtures were orally administered to awake rats at $0.68 \mathrm{~g} / 4.7 \mathrm{~mL} / \mathrm{kg}$. Blood glucose levels measured at 5, 15, 30, $45,60,90$, and $120 \mathrm{~min}$ after the administration. The change of blood glucose level $\left(\Delta C_{n}\right)$ was calculated from the value of $C_{0}$ and the value at $\mathrm{n}$ minutes after ingestion $\left(C_{n}\right)$ as follows:

$$
\Delta C_{n}=C_{n}-C_{0}
$$

Further, the postprandial elapsed time showing the highest blood glucose level $C_{\max }$ was designated $T_{\max }$, and the difference between $C_{\max }$ and $C_{0}$ was calculated as $\Delta C_{\max }$. In addition, the area under the blood glucose level-time curve $\triangle A U C$ in the feeding period 0 to $120 \mathrm{~min}$ was calculated from the $\Delta C_{n}$ values.

Statistical Analysis In the in vitro test, measurement was performed in triplicate. The results are shown as the mean \pm standard deviation (S.D.). Dunnett's test was used for comparisons, with a significance level of 5 or $1 \%$. 


\section{RESULTS}

Effect on $\boldsymbol{\alpha}$-Amylase Activity Maltose production rate was $99.9 \pm 1.2 \%$ for $\mathrm{Alg} 0.68 \mathrm{mg} / \mathrm{mL}, 98.4 \pm 1.4 \%$ for $\mathrm{Alg}$ $1.36 \mathrm{mg} / \mathrm{mL}$, and $97.9 \pm 3.2 \%$ for Alg $2.73 \mathrm{mg} / \mathrm{mL}$ (mean \pm S.D. $(n=3))$. Although the inhibition rate tended to increase depending on the Ca-Alg concentration, the differences are not statistically significant (Supplementary Fig. 1).

Effect on $\boldsymbol{\alpha}$-Glucosidase Activity The glucose production rate was $99.0 \pm 0.1 \%$ for Ca-Alg $1.36 \mathrm{mg} / \mathrm{mL}, 61.8 \pm 0.4 \%$ for Ca-Alg $2.73 \mathrm{mg} / \mathrm{mL}$, and $49.2 \pm 1.7 \%$ for acarbose $1 \mu \mathrm{g} / \mathrm{mL}$ as the positive control (mean \pm S.D. $(n=3)$ ) (Fig. 1). Notably, there was no significant change compared to the control when $\mathrm{Na}$ Alg was used.

Affinity of Alg and Glucose The amount of glucose adsorbed on $\mathrm{Ca}-\mathrm{Alg}$ increased with increasing initial glucose concentration until it reached saturation (Fig. 2). The maximum adsorption amount, $V_{\max }$, was $5.23(\mu \mathrm{mol} / \mathrm{mg} \mathrm{Na}-\mathrm{Alg})$, and the binding constant, $K_{\mathrm{m}}$, was $201.6 \mathrm{~mm}$. Na-Alg showed similar affinity.

Effect of Na-Alg on Membrane Permeability of Glucose The values (mean \pm S.D. $\left.(n=3) ; 10^{-3} \mathrm{~cm} / \mathrm{s}\right)$ of the permeation coefficient were $0.78 \pm 0.10$ (no Na-Alg), 0.83 \pm 0.06 (Na-Alg $0.1 \%$, and $0.72 \pm 0.07$ (Na-Alg $0.5 \%$ ). These values are not

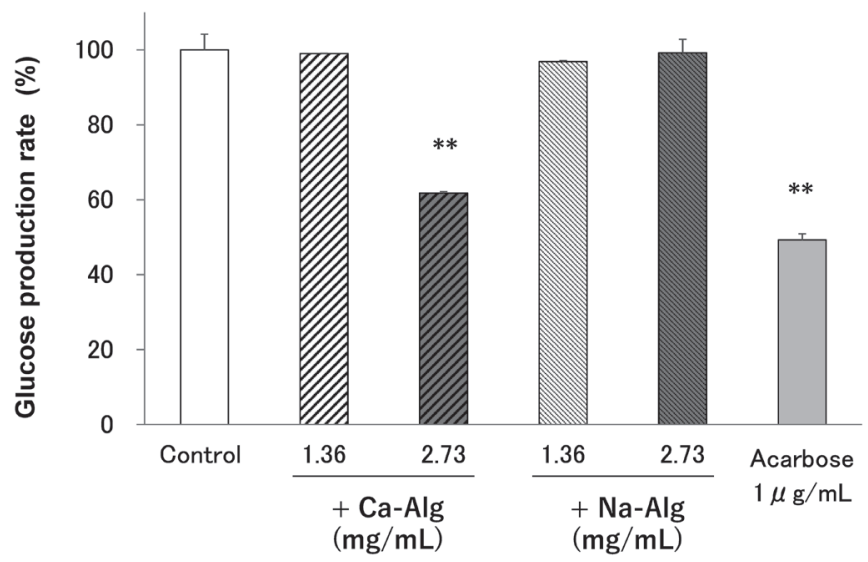

Fig. 1. Inhibitory Effect of Ca-Alg and Na-Alg on $\alpha$-Glucosidase Activity Glucose production rate was defined as compared with control reaction in which glucose produced was $100 \%$. The data are mean \pm S.D. $(n=3)$. significantly different, indicating that Na-Alg had no effect on the membrane permeability of glucose. On the other hand, the permeability coefficient was $0.17 \pm 0.01$ in the presence of $500 \mu \mathrm{M}$ phloretin, a GLUT 2 inhibitor, which is significantly different from the above values ( $p<0.01$, Dunnett's test) (Supplementary Fig. 2).

Optimum Blending Amount and Particle Size of CaAlg in Vivo When starch containing no Ca-Alg was orally administered to rats, the peak blood glucose level was $145.5 \pm 21.5 \mathrm{mg} / \mathrm{dL}$ at $30.0 \pm 17.3 \mathrm{~min}$ after the administration. $\Delta C_{\max }$ was $53.8 \pm 20.3 \mathrm{mg} / \mathrm{dL}$, and $\triangle A U C$ was $3551 \pm 2048 \mathrm{mg} \cdot \mathrm{min} / \mathrm{dL}$. However, when starch containing $5 \%$ Ca-Alg (particle size; 270 mesh pass) was administered, the $\Delta C_{\max }$ was significantly decreased to $25.0 \pm 19.9 \mathrm{mg} / \mathrm{dL}$, and the $\triangle A U C$ was significantly decreased to $561 \pm 2303 \mathrm{mg} \cdot \mathrm{min} / \mathrm{dL}$ (Fig. 3). However, the 3\% 270-mesh-pass Ca-Alg, or 5\% 150 or 80-mesh-pass Ca-Alg showed no significant difference in $\Delta C_{\max }$ or $\triangle A U C$ compared with the $0 \%$ Ca-Alg diet (Fig. 3).

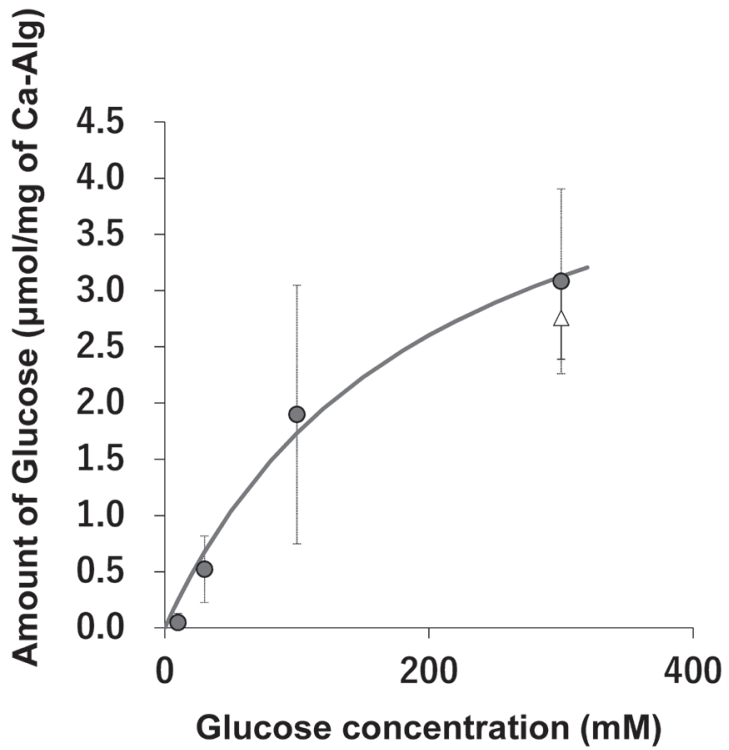

Fig. 2. Relationship between the Initial Concentration of Glucose and the Amount of Glucose Bound to Ca-Alg. $\bigcirc$ : Ca-Alg, $\triangle$ : Na-Alg

The data are mean \pm S.D. $(n=3)$.

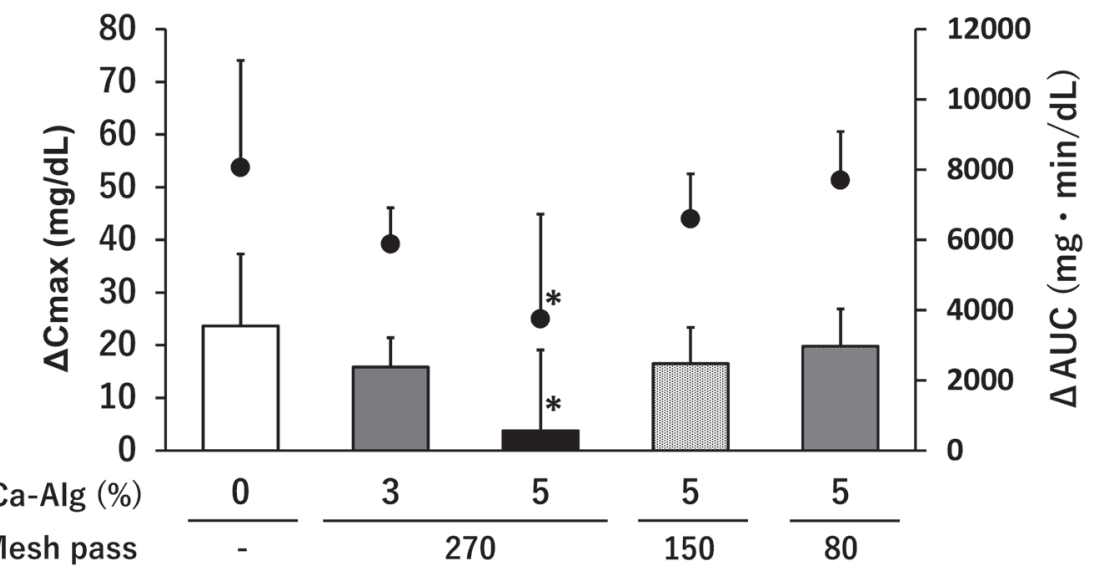

Fig. 3. Effect of Starch Diets Containing Ca-Alg on Blood Glucose Level in Rats

(A) Circles : $\Delta C_{\max }$, the difference between the maximum blood glucose level $C_{\max }$ and the pre-feeding blood glucose level $C_{0}$. (B) Bars : $\triangle A U C$, the difference between the area under the blood glucose level-time curve from 0 to $120 \mathrm{~min}$ after ingestion and the baseline value $C_{0}$. The data are mean \pm S.D., $n=3$ or 4 . $* p<0.05$, compared with control. 


\section{DISCUSSION}

In the gastrointestinal tract, starch is mainly decomposed into maltose by $\alpha$-amylase and then degraded to glucose by $\alpha$-glucosidase. Ca-Alg might affect postprandial changes of blood glucose levels in various ways. However, our results indicate that it acts predominantly by inhibiting $\alpha$-glucosidase. We ruled out a substantial contribution of direct binding, because the $K_{\mathrm{m}}$ value of Ca-Alg and glucose was $201.6 \mathrm{~mm}$, suggesting only weak binding compared to the binding constants of Alg and metals reported previously. ${ }^{26)}$ In addition, Ca-Alg did not affect the membrane transport of glucose.

An in vitro study has shown that the addition of polysaccharides increases the viscosity of starch suspension, and there is a positive correlation between the apparent viscosity and the decrease in starch digestion. ${ }^{27)}$ In addition, it is reported that inhibition of glucose absorption by dietary fiber is positively correlated to viscosity, ${ }^{28)}$ and starch digestion was suppressed by adding a thickener, ${ }^{29)}$ causing a lowering of the blood glucose level in clinical trials. Moreover, the postprandial blood glucose level is decreased by glucose-based beverages containing $\mathrm{Alg}$ and $\mathrm{Ca}^{2+}$, and it was speculated that one reason for this could be that the beverage becomes more viscous in the digestive tract due to the interaction between $\mathrm{Ca}^{2+}$ and Alg. ${ }^{30)}$ We speculate that $\mathrm{Ca}-\mathrm{Alg}$ interfered physically with contact between $\alpha$-glucosidase and maltose by increasing the viscosity of the intestinal contents.

The in vivo study in rats established that $5 \%$ of 270 -meshpass $\mathrm{Ca}-\mathrm{Alg}$ was the most effective amount and particle size combination to suppress the postprandial increase of blood glucose. Both $\triangle C_{\max }$ and $\triangle A U C$ were significantly decreased, compared with $0 \% \mathrm{Ca}-\mathrm{Alg}$, meaning that both the postprandial peak glucose level and the total amount of glucose absorbed by $2 \mathrm{~h}$ after the meal were decreased. Since the surface area is inversely proportional to the particle diameter for the same weight (volume), the surface area ratio of $\mathrm{Alg}(80: 150: 270$ mesh pass) is $1: 2.8: 9.6$. It is considered that the difference in surface area would affect the magnitude of action.

Thus, the in vitro and in vivo results support the idea that Ca-Alg increases the viscosity of the gastrointestinal contents, depending upon the surface area of the gel. This in turn may inhibit the interaction between $\alpha$-glucosidase and maltose as a substrate, thereby suppressing the production of glucose, and preventing a sharp rise in blood glucose level.

Various other products have been reported to moderate glucose absorption, including indigestible dextrin (a dietary fiber made from corn starch), salacinol derived from plant salacia, proanthocyanidin derived from acacia, and degradation products of guar gum (an edible cluster bean ingredient). ${ }^{31-36)}$ Among them, indigestible dextrin has been confirmed to suppress the postprandial increase in blood glucose level by inhibiting $\alpha$-glucosidase ${ }^{35}$ ) and it is widely used as a food for specified health use and as a functional food. It seems reasonable to consider that $\mathrm{Ca}-\mathrm{Alg}$ works similarly. It will be interesting to see whether Ca-Alg also improves other parameters of lifestyle-related diseases. ${ }^{31)}$ We believe the present result warrant a clinical trial to see whether the effect of Ca-Alg on postprandial glucose levels can be reproduced in humans.

Conflict of Interest Kazuyo Shiragami, Mariko Koike are employees of Shimadaya Corporation. The other authors have no potential conflict of interest.

Supplementary Materials The online version of this article contains supplementary materials.

\section{REFERENCES}

1) WHO. "Global status report on noncommunicable diseases 2014.": 〈http://www.who.int/nmh/publications/ncd-status-report-2014/en/〉, World Health Organization, Geneva (2014).

2) Watanabe T. Food and disease: The etiological background of socalled lifestyle-related diseases. J. Jpn. Soc. Nutr. Food Sci., 57, 15-19 (2004).

3) "Analysis by cause of death.": 〈http://www.mhlw.go.jp/english/ database/db-hw/lifetb16/d1/lifetb16-04.pdf), Ministry of Health, Labour and Welfare (2016).

4) Kitamura A, Iso H, Naito $Y$, Iida M, Konishi M, Folsom AR, Sato S, Kiyama M, Nakamura M, Sankai T, Shimamoto T, Komachi Y. High-density lipoprotein cholesterol and premature coronary heart disease in urban Japanese men. Circulation, 89, 2533-2539 (1994).

5) Iso $\mathrm{H}$, Naito $\mathrm{Y}$, Sato $\mathrm{S}$, Kitamura A, Okamura $\mathrm{T}$, Sankai $\mathrm{T}$ Shimamoto T, Iida M, Komachi Y. Serum triglycerides and risk of coronary heart disease among Japanese men and women. Am. J. Epidemiol., 153, 490-499 (2001).

6) Lida M, Ueda K, Okayama A, Kodama K, Sawai K, Shibata S, Tanaka S, Keijnkai T, Horibe H, Minowa M, Yanagawa H, Hashimoto T, NIPPON DATA80 Research Group. Impact of elevated blood pressure on mortality from all causes, cardiovascular diseases, heart disease and stroke among Japanese: 14 year follow-up of randomly selected population from Japanese (Nippon Data 80). J. Hum. Hypertens., 17, 851-857 (2003).

7) Teramoto T. Dietary management in Japan Atherosclerosis Society (JAS) guidelines for the prevention of atherosclerotic cardiovascular diseases in Japanese-2012 Version-. The Japanese Journal of Nutrition and Dietetics, 71, 3-13 (2013).

8) Abifadel M, Varret M, Rabès JP, Allard D, Ouguerram K, Devillers M, Cruaud C, Benjannet S, Wickham L, Erlich D, Derré A, Villéger L, Farnier M, Beucler I, Bruckert E, Chambaz J, Chanu B, Lecerf JM, Luc G, Moulin P, Weissenbach J, Prat A, Krempf M, Junien C, Seidah NG, Boileau C. Mutations in PCSK9 cause autosomal dominant hypercholesterolemia. Nat. Genet., 34, 154-156 (2003).

9) Eguchi Y, Eguchi T, Mizuta T, Ide Y, Yasutake T, Iwakiri R, Hisatomi A, Ozaki I, Yamamoto K, Kitajima Y, Kawaguchi Y, Kuroki $\mathrm{S}$, Ono N. Visceral fat accumulation and insulin resistance are important factors in nonalcoholic fatty liver disease. J. Gastroenterol., 41, 462-469 (2006).

10) Stamler J, Rose G, Stamler R, Elliott P, Dyer A, Marmot M. INTERSALT study findings. Public health and medical care implications. Hypertension, 14, 570-577 (1989).

11) Tajima N, Noda M, Origasa H, Noto H, Yabe D, Fujita Y, Goto A, Fujimoto K, Sakamoto M, Haneda M, The Japan Diabetes Society. Evidence-based practice guideline for the treatment for diabetes in Japan 2013. Diabetol. Int., 6, 151-187 (2015).

12) Kopf D, Frölich L. Risk of incident Alzheimer's disease in diabetic patients: A systematic review of prospective trials. J. Alzheimer's Dis., 16, 677-685 (2009).

13) "The National Health and Nutrition Survey in Japan, 2016.": 〈http://www.mhlw.go.jp/bunya/kenkou/eiyou/d1/h28-houkoku.pdf〉, Ministry of Health, Labor and Welfare, cited 2017.

14) “Diabetes.": 〈http://www1.mhlw.go.jp/topics/kenko21_11/pdf/b7.pdf〉, Ministry of Health, Labor and Welfare.

15) Kahn SE. The relative contributions of insulin resistance and betacell dysfunction to the pathophysiology of type 2 diabetes. Diabetologia, 46, 3-19 (2003).

16) Kagawa Y. Prevention of lifestyle-related diseases by chronological nutrition. Jpn. J. Phys. Fitness Sports Med., 63, 293-304 (2014). 
17) Kimica Corporation Web.: 〈http://www.kimica-alginate.com/alginate/chemical_structure.html>, 2009.

18) Nishizawa M, Kuda T, Yamagishi $T$, Tsuji K. Effect of depolymerized sodium alginate on the excretion of cholesterol from rats. $J$. Home Econ. Jpn., 48, 689-693 (1997).

19) Georg Jensen M, Kristensen M, Astrup A. Effect of alginate supplementation on weight loss in obese subjects completing a 12-week energy-restricted diet: a randomized controlled trial. Am. J. Clin. Nutr., 96, 5-13 (2012).

20) Peters HP, Koppert RJ, Boers HM, Ström A, Melnikov SM, Haddeman E, Schuring EA, Mela DJ, Wiseman SA. Dose-dependent suppression of hunger by a specific alginate in a low-viscosity drink formulation. Obesity, 19, 1171-1176 (2011).

21) Fujita T, Henry WL, Bartter FC, Lake CR, Delea CS. Factors influencing blood pressure in salt-sensitive patients with hypertension. Am. J. Med., 69, 334-344 (1980).

22) Idota $Y$, Harada $H$, Tomono $T$, Morimoto $K$, Kobayashi S, Kakinuma C, Miyajima C, Kasahara F, Ogihara T. Alginate enhances excretion and reduces absorption of strontium and cesium in rats. Biol. Pharm. Bull., 36, 485-491 (2013).

23) Idota Y, Kogure Y, Kato T, Ogawa M, Kobayashi S, Kakinuma C, Yano K, Arakawa H, Miyajima C, Kasahara F, Ogihara T. Cholesterol-lowering effect of calcium alginate in rats. Biol. Pharm. Bull., 39, 62-67 (2016)

24) Sawabe A, Fukuda Y, Ueno M, Kawachi Y, Takeda R, Komemushi S. Effect of postcibal blood triglyceride level and blood glucose level by single intake of calcium alginate content food for adult men. Dietary Research, 33, 41-46 (2013).

25) Ogihara T, Tamai I, Takanaga H, Sai Y, Tsuji A. Stereoselective and carrier-mediated transport of monocarboxylic acids across Caco-2 cells. Pharm. Res., 13, 1828-1832 (1996).

26) Idota Y, Kogure Y, Kato T, Yano K, Arakawa H, Miyajima C, Kasahara F, Ogihara T. Relationship between physical parameters of various metal ions and binding affinity for alginate. Biol. Pharm. Bull., 39, 1893-1896 (2016).

27) Sasaki T, Kohyama K. Influence of non-starch polysaccharides on the in vitro digestibility and viscosity of starch suspensions. Food
Chem., 133, 1420-1426 (2012).

28) Jenkins DJ, Wolever TM, Leeds AR, Gassull MA, Haisman P, Dilawari J, Goff DV, Metz GL, Alberti KG. Dietary fibres, fibre analogues, and glucose tolerance: importance of viscosity. $B M J, \mathbf{1}$, 1392-1394 (1978)

29) Sagawa A, Nakanishi $Y$, Ono H, Moritaka H. Effects of added thickeners on the digestibility of cooked rice and mechanical properties of cooked rice bolus. Nippon Shokuhin Kagaku Kogaku Kaishi, 60, 387-396 (2013).

30) Wolf BW, Lai CS, Kipnes MS, Ataya DG, Wheeler KB, Zinker BA, Garleb KA, Firkins JL. Glycemic and insulinemic responses of nondiabetic healthy adult subjects to an experimental acid-induced viscosity complex incorporated into a glucose beverage. Nutrition, 18, 621-626 (2002).

31) Kishinaga Y, Yamada F, Nambu S. Effects of the coffee containing resistant maltodextrin on postprandial blood glucose level-a randomized double-blindcrossover study-. Jpn. Pharmacol. Ther, 42, 347-351 (2014).

32) Ikarashi N, Takeda R, Ito K, Ochiai W, Sugiyama K. The inhibition of lipase and glucosidase activities by acacia polyphenol. Evid. Based Complement. Alternat. Med., 2011, 272075 (2011).

33) Takahashi T, Yokawa T, Ishihara N, Okubo T, Chu DC, Nishigaki E, Kawada Y, Kato M, Raj Juneja L. Hydrolyzed guar gum decreases postprandial blood glucose and glucose absorption in the rat small intestine. Nutr. Res., 29, 419-425 (2009).

34) Kusano R, Ogawa S, Matsuo Y, Tanaka T, Yazaki Y, Kouno I. $\alpha$-Amylase and lipase inhibitory activity and structural characterization of acacia bark proanthocyanidins. J. Nat. Prod., 74, 119-128 (2011).

35) Tashiro M, Kato M. Effect of administration of indigestible dextrin prepared from corn starch on glucose tolerance in streptozotocindiabetic rats. J. Jpn. Soc. Nutr. Food Sci., 52, 21-29 (1999).

36) Heacock PM, Hertzler SR, Williams JA, Wolf BW. Effects of a medical food containing an herbal alpha-glucosidase inhibitor on postprandial glycemia and insulinemia in healthy adults. J. Am. Diet. Assoc., 105, 65-71 (2005). 